\title{
Coupled Fixed Point Theorems for W-Compatible Maps Relaxing Continuity in Partially Ordered G-Metric Spaces
}

\author{
Sunil Kumar \\ N.S.S.School. \\ Bhuna,Fatehabad \\ (Haryana) India
}

\author{
Rakesh Kumar \\ Department of Mathematics \\ G.J.U.\&S.T. \\ Hisar (Haryana) India
}

\begin{abstract}
In this paper, we have established coupled coincidence point results for pair of mappings in partially ordered G-metric spaces. We have defined w-compatibility in this context to ensure the uniqueness of the coupled common fixed point.There are several corollaries which extend some known results of coupled coincidence points and coupled fixed points. The main theorem is illustrated with an example. The example demonstrates that our main result is an actual improvement over the results which are generalized.
\end{abstract}

\section{General Terms:}

2000 Mathematics Subject:- 47H10, 54H25.

\section{Keywords:}

Partially ordered set, coupled coincidence point, mixed gmonotone property, compatible mappings, w-compatible mappings.

\section{MATHEMATICAL PRELIMINARIES}

In 2004, Mustafa and Sims [2] introduced the concept of $G$-metric spaces as follows:

Definition 1.1. [19] Let $X$ be a nonempty set and let $G$ : $X \times X \times X \longrightarrow R_{+}$be a function satisfying the following properties

(G1) $G(x, y, z)=0$ if $x=y=z$,

(G2) $0<G(x, x, y)$ for all $x, y \in X$, with $x \neq y$,

(G3) $G(x, x, y) \leq G(x, y, z)$ for all $x, y, z \in X$, with $y \neq z$

(G4) $G(x, y, z)=G(x, z, y)=G(y, z, x)=\ldots$, (symmetry in all three variables),

(G5) $G(x, y, z) \leq G(x,, a, a)+G(a, y, z)$, for all $x, y, z, a \in X$, (rectangle inequality).

Then the function $G$ is called a generalized metric, or, more specially, a $G$-metric on $X$, and the pair $(X, G)$ is called a $G$-metric space.

Definition 1.2. [19] Let $(X, G)$ be a $G$-metric space and let $\left(x_{n}\right)$ be a sequence of points of $X$, a point $x \in X$ is said to be the limit of the sequence $\left(x_{n}\right)$, if $\lim _{n, m \rightarrow+\infty} G\left(x, x_{n}, x_{m}\right)=0$, and we say that the sequence $\left(x_{n}\right)$ is $G$-convergent to $x$ or $\left(x_{n}\right) G$ converges to $x$.

Thus, $x_{n} \rightarrow x$ in a $G$-metric space $(X, G)$ if for any $\varepsilon>0$ there exists $k \in \mathbb{N}$ such that $G\left(x, x_{n}, x_{m}\right)<\varepsilon$ for all $m, n \geq k$.

Proposition 1.3. [19] Let $(X, G)$ be a $G$-metric space. Then, the following are equivalent

(1) $\left\{x_{n}\right\}$ is $G$-convergent to $x$

(2) $G\left(x_{n}, x_{n}, x\right) \rightarrow 0$ as $n \rightarrow+\infty$

(3) $G\left(x_{n}, x, x\right) \rightarrow 0$ as $n \rightarrow+\infty$

(4) $G\left(x_{n}, x_{m}, x\right) \rightarrow 0$ as $n, m \rightarrow+\infty$.

Proposition 1.4. [19] Let $(X, G)$ be a $G$-metric space. Then $f: X \rightarrow X$ is $G$-continuous at $x \in X$ if and only if it is $G$-sequentially continuous at $x$, that is, whenever $\left(x_{n}\right)$ is $G$ convergent to $x,\left(f\left(x_{n}\right)\right)$ is $G$-convergent to $f(x)$.

Proposition 1.5. [19] Let $(X, G)$ be a G-metric space. Then the function $G(x, y, z)$ is jointly continuous in all three of its variables.

Definition 1.6. (see [9]). Let $(X, G)$ be a G-metric space. A mapping $F: X \times X \rightarrow X$ is said to be continuous if for any two $G$-convergent sequences $\left\{x_{n}\right\}$ and $\left\{y_{n}\right\}$ converging to $x$ and $y$ respectively, $\left\{F\left(x_{n}, y_{n}\right)\right\}$ is $G$-convergent to $F(x, y)$.

Definition 1.7. [19] A G-metric space $(X, G)$ is called $G$ complete if every $G$-Cauchy sequence is $G$-convergent in $(X, G)$.

DEFINITION 1.8. A G-metric space $(X, G)$ is called a symmetric $G$-metric space if $G(x, y, y)=G(y, x, x)$ for all $x, y \in X$.

Proposition 1.9. [19] (i) Every G-metric space $(X, G)$ will define a metric space $\left(X, d_{G}\right)$ by $d_{G}(x, y)=G(x, y, y)+$ $G(y, x, x)$ for all $x, y \in X$.

(ii) If $(X, G)$ is a symmetric $G$-metric space, then $d_{G}(x, y)=$ $2 G(x, y, y)$ for all $x, y$ in $X$.

(iii) However, if $(X, G)$ is not symmetric, then it follows from the $G$-metric properties that

$$
3 / 2 G(x, y, y) \leq d_{G}(x, y) \leq 3 G(x, y, y) \text { forall } x \text {, yin } X .
$$

The concept of a mixed monotone property has been introduced by Bhaskar and Lakshmikantham in [6]. 
DEFINITION 1.10. (see [6]). Let $(X, \preceq)$ be a partially ordered set. A mapping $F: X \times X \rightarrow X$ is said to have mixed monotone property if $F(x, y)$ is monotone non-decreasing in $x$ and is monotone non-increasing in $y$; that is, for any $x, y \in X$,

$$
\begin{array}{rlrl}
x_{1}, x_{2} \in X, & x_{1} \preceq x_{2} \quad \text { implies } & F\left(x_{1}, y\right) & \preceq F\left(x_{2}, y\right), \\
y_{1}, y_{2} \in X, \quad y_{1} \preceq y_{2} \quad \text { implies } & F\left(x, y_{2}\right) \preceq F\left(x, y_{1}\right) .
\end{array}
$$

Lakshmikantham and Ćirić in [16] introduced the concept of a $g$ mixed monotone mapping.

DEFINITION 1.11. (see [16]). Let $(X, \preceq)$ be a partially ordered set. Let us consider mappings $F: X \times X \rightarrow X$ and $g: X \rightarrow X$. The map $F$ is said to have mixed $g$-monotone property if $F(x, y)$ is monotone $g$-non-decreasing in $x$ and is monotone $g$-non-increasing in $y$; that is, for any $x, y \in X$,

$$
\begin{array}{rlrl}
x_{1}, x_{2} \in X, & g x_{1} \preceq g x_{2} \quad \text { implies } & F\left(x_{1}, y\right) \preceq F\left(x_{2}, y\right), \\
y_{1}, y_{2} \in X, \quad g y_{1} \preceq g y_{2} \quad \text { implies } & F\left(x, y_{2}\right) \preceq F\left(x, y_{1}\right) .
\end{array}
$$

Definition 1.12. (see [6]). An element $(x, y) \in X \times X$ is called a coupled fixed point of a mapping $F: X \times X \rightarrow X$ if

$$
F(x, y)=x \quad \text { and } \quad F(y, x)=y .
$$

Definition 1.13. (see [16]). An element $(x, y) \in X \times X$ is called a coupled coincidence point of the mappings $F: X \times X \rightarrow$ $X$ and $g: X \rightarrow X$ if

$$
F(x, y)=g x \quad \text { and } \quad F(y, x)=g y .
$$

DEFINITION 1.14. (see [16]). We say that mappings $F: X \times$ $X \rightarrow X$ and $g: X \rightarrow X$ are commutative if

$$
g(F(x, y))=F(g x, g y) \text { for all } x, y \in X .
$$

DeFinition 1.15. [2] The mappings $F: X \times X \rightarrow X$ and $g: X \rightarrow X$ are called $w$-compatible if $g(F(x, y))=F(g x, g y)$ whenever $g(x)=F(x, y)$ and $g(y)=F(y, x)$.

Using the concept of continuous, mixed monotone property and coupled fixed point, Choudhary and Maity [9] introduced the following theorem:

THEOREM 1.16. Let $(X, \preceq)$ be a partially ordered set and let $G$ be a $G$-metric on $X$ such that $(X, G)$ is a complete $G$-metric space. Let $F: X \times X \rightarrow X$ be a continuous mapping having mixed monotone property on $X$. Assume that there exist a $k \in[0,1)$ such that for $x, y, u, v, w, z \in X$, the following holds

$$
G(F(x, y), F(u, v), F(w, z)) \leq \frac{k}{2}[G(x, u, w)+G(y, v, z)],
$$

for all $x \succeq u \succeq w$ and $y \preceq v \preceq z$ where either $u \neq w$ or $v \neq z$. If there exist $x_{0}$ and $\bar{y}_{0} \in \bar{X}$, such that $x_{0} \preceq F\left(x_{0}, y_{0}\right)$ and $y_{0} \succeq F\left(y_{0}, x_{0}\right)$, then $F$ has a coupled fixed point in $X$, that is, there exist $x, y \in X$ such that $x=F(x, y)$ and $y=F(y, x)$.

We denote by $\Phi$ the set of functions $\phi:[0,+\infty) \rightarrow[0,+\infty)$ satisfying

(a) $\phi^{-1}(\{0\})=\{0\}$,

(b) $\phi(t)<t$ for all $t>0$,

(c) $\lim _{r \rightarrow t^{+}} \phi(r)<t$ for all $t>0$.

Very recently, Aydi et al. [5] generalized the above theorem using commutative mappings and $g$-mixed monotone property in the following way:
THEOREM 1.17. Let $(X, \preceq)$ be a partially ordered set and $G$ be a $G$-metric on $X$ such that $(X, G)$ is a complete $G$-metric space. Suppose that there exist $\phi \in \Phi, F: X \times X \rightarrow X$ and $g: X \rightarrow X$ such that

$G(F(x, y), F(u, v), F(w, z)) \leq \phi\left(\frac{G(g x, g u, g w)+G(g y, g v, g z)}{2}\right)$

for all $x, y, u, v, w, z \in X$ with $g w \preceq g u \preceq g x$ and $g y \preceq$ $g v \preceq g z$. Suppose also that $F$ is continuous and has the mixed g-monotone property, $F(X \times X) \subseteq g(X)$ and $g$ is continuous and commutes with $F$. If there exist $x_{0}, y_{0} \in X$ such that $g x_{0} \preceq F\left(x_{0}, y_{0}\right)$ and $F\left(y_{0}, x_{0}\right) \preceq g y_{0}$, then $F$ and $g$ have $a$ coupled coincidence point, that is, there exists $(x, y) \in X \times X$ such that $g x=F(x, y)$ and $g y=F(y, x)$.

Motivated by [8], we define the notion of compatibility in the following:

Definition 1.18. Let $F: X \times X \rightarrow X$ and $g: X \rightarrow X$. The mappings $F$ and $g$ are said to be compatible if

$$
\lim _{n \rightarrow \infty} G\left(g\left(F\left(x_{n}, y_{n}\right)\right), F\left(g x_{n}, g y_{n}\right), F\left(g x_{n}, g y_{n}\right)\right)=0,
$$

and

$$
\lim _{n \rightarrow \infty} G\left(g\left(F\left(y_{n}, x_{n}\right)\right), F\left(g y_{n}, g x_{n}\right), F\left(g y_{n}, g x_{n}\right)\right)=0,
$$

whenever $\left\{x_{n}\right\}$ and $\left\{y_{n}\right\}$ are sequences in $X$ such that $\lim _{n \rightarrow \infty} F\left(x_{n}, y_{n}\right)=\lim _{n \rightarrow \infty} g\left(x_{n}\right)$ and $\lim _{n \rightarrow \infty} F\left(y_{n}, x_{n}\right)=$ $\lim _{n \rightarrow \infty} g\left(y_{n}\right)$ for all $x, y \in X$ are satisfied.

Now we introduce the notion of w-compatibility in the in the setting of G-metric space as following:

Definition 1.19. Let $F: X \times X \rightarrow X$ and $g: X \rightarrow$ $X$. The mappings $F$ and $g$ are said to be $w$-compatible if $G(g(F(x, y)), F(g x, g y), F(g x, g y))=0$ whenever $F(x, y)=$ $g x$ and $F(y, x)=g y$.

\section{MAIN RESULTS}

Our first result is the following:

THEOREM 2.1. Let $(X, \preceq)$ be a partially ordered set and $G$ be a $G$-metric on $X$. Let $F: X \times X \rightarrow X$ and $g: X \rightarrow X$ such that $F$ has the mixed g-monotone property. Suppose there exist nonnegative real numbers $p, \alpha, \beta$ and $L$ with $\alpha+\beta<1$ such that

$$
\begin{aligned}
& G(F(x, y), F(u, v), F(w, z)) \\
& \leq p G(F(w, z), g y, g v) \frac{G(F(x, y), g x, g w)}{1+G(F(y, x), g v, g z)} \\
&+ \alpha G(g x, g u, g w)+\beta G(g y, g v, g z) \\
&+ L \min \{G(F(x, y), g u, g w), G(F(w, z), g x, g u), \\
&\quad G(F(y, x), g v, g z), G(F(u, v), g x, g w))\},
\end{aligned}
$$

for all $x, y, u, v, w, z \in X$ with $g w \preceq g u \preceq g x$ and $g y \preceq g v \preceq$ $g z$. Suppose that $F(X \times X) \subseteq g(\bar{X})$ and $g(X)$ is a complete subset of $X$. Assume also $X$ satifies:

(i) if a non-decreasing sequence $\left(x_{n}\right)$ is such that $x_{n} \rightarrow x$, then $x_{n} \preceq x$ for all $n$,

(ii) if a non-increasing sequence $\left(y_{n}\right)$ is such that $y_{n} \rightarrow y$, then $y \preceq y_{n}$ for all $n$.

If there exist $x_{0}, y_{0} \in X$ such that $g x_{0} \preceq F\left(x_{0}, y_{0}\right)$ and $F\left(y_{0}, x_{0}\right) \preceq g y_{0}$, then $F$ and $g$ have a coupled coincidence point, 
that is, there exists $(x, y) \in X \times X$ such that $g x=F(x, y)$ and $g y=F(y, x)$.

PROOF. Let $x_{0}, y_{0}$ be such that $g x_{0} \preceq F\left(x_{0}, y_{0}\right)$ and $g y_{0} \succeq$ $F\left(y_{0}, x_{0}\right)$. Since $F(X \times X) \subseteq g(X)$, we can choose $x_{1}, y_{1} \in \bar{X}$ such that $g x_{1}=F\left(x_{0}, y_{0}\right)$ and $g y_{1}=F\left(y_{0}, x_{0}\right)$. Continuing like this we can construct two sequences $\left\{g x_{n}\right\}$ and $\left\{g y_{n}\right\}$ such that

$g x_{n}=F\left(x_{n-1}, y_{n-1}\right) \quad$ and $\quad g y_{n}=F\left(y_{n-1}, x_{n-1}\right) \quad \forall n \geq 1$.

Since $F$ has mixed g-monotone property, then it is obvious that

$$
g x_{n} \preceq g x_{n+1} \quad \text { and } \quad g y_{n+1} \preceq g y_{n} \quad \forall n \in \mathbb{N} \text {. }
$$

If for some integer $n$, we have $\left(g x_{n+1}, g y_{n+1}\right)=\left(g x_{n}, g y_{n}\right)$, then $F\left(x_{n}, y_{n}\right)=g x_{n}$ and $F\left(y_{n}, x_{n}\right)=g y_{n}$, that is, $F$ and $g$ have a coincidence point. So from now on, we assume $\left(g x_{n+1}, g y_{n+1}\right) \neq$ $\left(g x_{n}, g y_{n}\right)$ for all $n \in \mathbb{N}$, that is, we assume that either $g x_{n+1}=$ $F\left(x_{n}, y_{n}\right) \neq g x_{n}$ or $g y_{n+1}=F\left(y_{n}, x_{n}\right) \neq g y_{n}$. From 2.11, we have

$$
\begin{aligned}
& G\left(F\left(x_{n}, y_{n}\right), F\left(x_{n}, y_{n}\right), F\left(x_{n-1}, y_{n-1}\right)\right) \\
& \leq p G\left(F\left(y_{n-1}, x_{n-1}\right), g y_{n}, g y_{n}\right) \frac{G\left(F\left(x_{n}, y_{n}\right), g x_{n}, g x_{n-1}\right)}{\left.1+G\left(F\left(y_{n}, x_{n}\right), g y_{n}\right), g y_{n-1}\right)} \\
& +\alpha G\left(g x_{n}, g x_{n}, g x_{n-1}\right)+\beta G\left(g y_{n}, g y_{n}, g y_{n-1}\right) \\
& +L \min \left\{\left(G\left(F\left(x_{n}, y_{n}\right), g x_{n}, g x_{n-1}\right), G\left(F\left(x_{n-1}, y_{n-1}\right), g x_{n}, g x_{n}\right),\right.\right. \\
& \left.G\left(F\left(y_{n}, x_{n}\right), g y_{n}, g y_{n-1}\right), G\left(F\left(x_{n}, y_{n}\right), g x_{n}, g x_{n-1}\right)\right\},
\end{aligned}
$$

that is, thanks to 2.2 ,

$$
\begin{array}{r}
G\left(g x_{n+1}, g x_{n+1}, g x_{n}\right) \leq \alpha \\
G\left(g x_{n}, g x_{n}, g x_{n-1}\right)+\beta G\left(g y_{n}, g y_{n}, g y_{n-1}\right) .
\end{array}
$$

Similarly, we can prove

$$
\begin{array}{r}
G\left(g y_{n+1}, g y_{n+1}, g y_{n}\right) \leq \alpha \\
G\left(g y_{n}, g y_{n}, g y_{n-1}\right)+\beta G\left(g x_{n}, g x_{n}, g x_{n-1}\right) .
\end{array}
$$

adding 2.4 to 2.5 , we get that

$$
\begin{gathered}
G\left(g x_{n+1}, g x_{n+1}, g x_{n}\right)+G\left(g y_{n+1}, g y_{n+1}, g y_{n}\right) \\
\leq(\alpha+\beta)\left(G\left(g x_{n}, g x_{n}, g x_{n-1}\right)+G\left(g y_{n}, g y_{n}, g y_{n-1}\right)\right)
\end{gathered}
$$

Set, $d_{n}=G\left(g x_{n+1}, g x_{n+1}, g x_{n}\right)+G\left(g y_{n+1}, g y_{n+1}, g y_{n}\right)$ and $\delta=\alpha+\beta$. By (2.6), we have

$$
d_{n} \leq \delta d_{n-1} \leq \cdots \leq \delta^{n} d_{0}
$$

Since $\delta=\alpha+\beta<1$, then

$\lim _{n \rightarrow \infty} d_{n}=\lim _{n \rightarrow \infty}\left[G\left(g x_{n+1}, g x_{n+1}, g x_{n}\right)+G\left(g y_{n+1}, g y_{n+1}, g y_{n}\right)\right]=0$

Thus,

$$
\lim _{n \rightarrow \infty} G\left(g x_{n+1}, g x_{n+1}, g x_{n}\right)=\lim _{n \rightarrow \infty} G\left(g y_{n+1}, g y_{n+1}, g y_{n}\right)=0 .
$$

Next we show that $\left\{g x_{n}\right\}$ and $\left\{g y_{n}\right\}$ are $G$-Cauchy sequences. Let $m, n \in \mathbb{N}$ with $m<n$.

$$
\begin{aligned}
& G\left(g x_{m}, g x_{m}, g x_{n}\right)+G\left(g y_{m}, g y_{m}, g y_{n}\right) \\
& \leq G\left(g x_{m}, g x_{m+1}, g x_{m+1}\right)+G\left(g y_{m}, g y_{m+1}, g y_{m+1}\right) \\
& +G\left(g x_{m+1}, g x_{m+2}, g x_{m+2}\right)+G\left(g y_{m+1}, g y_{m+2}, g y_{m+2}\right) \\
& +\cdots+G\left(g x_{n-1}, g x_{n-1}, g x_{n}\right)+G\left(g y_{n-1}, g y_{n-1}, g y_{n}\right) \\
& =d_{m}+d_{m+1}+\cdots+d_{n-1} \\
& \leq\left(\delta^{m}+\delta^{m+1}+\cdots \delta^{n-1}\right) d_{0} \\
& \leq \frac{\delta^{m}}{1-\delta} d_{0} \rightarrow 0 \quad \text { as } \quad m \rightarrow \infty .
\end{aligned}
$$

Hence, $\quad \lim _{m, n \rightarrow \infty} G\left(g x_{m}, g x_{m}, g x_{n}\right)$

$\lim _{m, n \rightarrow \infty} G\left(g y_{m}, g y_{m}, g y_{n}\right)=0$. Therefore, both $\left\{g x_{n}\right\}$ and $\left\{g y_{n}\right\}$ are Cauchy sequences in $g(X)$. From the completeness of $g(X)$, there exist $x, y \in X$ such that

$$
\begin{gathered}
\lim _{n \rightarrow \infty} F\left(x_{n}, y_{n}\right)=\lim _{m, n \rightarrow \infty} g x_{n+1}=g x \quad \text { and } \\
\lim _{m, n \rightarrow \infty} F\left(y_{n}, x_{n}\right)=\lim _{m, n \rightarrow \infty} g y_{n+1}=g y .
\end{gathered}
$$

By the conditions (i)-(ii) and (2.3), 2.9, we get that, for all $n \geq 0$

$$
g x_{n} \preceq g x \text { and } g y \preceq g y_{n} .
$$

From 2.11)

$$
\begin{aligned}
& G\left(F(x, y), F(x, y), F\left(x_{n-1}, y_{n-1}\right)\right) \\
& \leq p G\left(F\left(y_{n-1}, x_{n-1}\right), g y, g y\right) \frac{G\left(F(x, y), g x, g x_{n-1}\right)}{1+G\left(F(y, x), g y, g y_{n-1}\right)} \\
+ & \alpha G\left(g x, g x, g x_{n-1}\right)+\beta G\left(g y, g y, g y_{n-1}\right) \\
+ & L \min \left\{G\left(F(x, y), g x, g x_{n-1}\right), G\left(F\left(x_{n-1}, y_{n-1}\right), g x, g x\right),\right. \\
& \left.G\left(F(y, x), g y, g y_{n-1}\right), G\left(F(x, y), g x, g x_{n-1}\right)\right\} .
\end{aligned}
$$

Letting the limit as $n \rightarrow \infty$ in the above inequality, using (2.9), we have $G(F(x, y), F(x, y), g x)=0$, that is, $g x=F(x, y)$. Using the same idea, we obtain $g y=F(y, x)$. We have proved that $(x, y)$ is a coupled coincidence of $F$ and $g$. This completes the proof of Theorem 1.17 $\square$

Setting $L=0$ in Theorem 3.1, we have following corollary:

COROLlaRY 2.2. Let $(X, \preceq)$ be a partially ordered set and $G$ be a G-metric on $X$. Let $F: X \times X \rightarrow X$ and $g: X \rightarrow X$ such that $F$ has the mixed $g$-monotone property. Suppose there exist non-negative real numbers $p, \alpha, \beta$ with $\alpha+\beta<1$ such that

$$
\begin{aligned}
& G(F(x, y), F(u, v), F(w, z)) \\
& \leq p G(F(w, z), g y, g v) \frac{G(F(x, y), g x, g w)}{1+G(F(y, x), g v, g z)} \\
& +\alpha G(g x, g u, g w)+\beta G(g y, g v, g z)
\end{aligned}
$$

for all $x, y, u, v, w, z \in X$ with $g w \preceq g u \preceq g x$ and $g y \preceq g v \preceq$ $g z$. Suppose that $F(X \times X) \subseteq g(X)$ and $g(X)$ is a complete subset of $X$. Assume also $X$ satifies:

(i) if a non-decreasing sequence $\left(x_{n}\right)$ is such that $x_{n} \rightarrow x$, then $x_{n} \preceq x$ for all $n$,

(ii) if a non-increasing sequence $\left(y_{n}\right)$ is such that $y_{n} \rightarrow y$, then $y \preceq y_{n}$ for all $n$. If there exist $x_{0}, y_{0} \in X$ such that $g x_{0} \preceq$ $F\left(x_{0}, y_{0}\right)$ and $F\left(y_{0}, x_{0}\right) \preceq g y_{0}$, then $F$ and $g$ have a coupled coincidence point, that is, there exists $(x, y) \in X \times X$ such that $g x=F(x, y)$ and $g y=F(y, x)$. 
Again, setting $p=0$ in Corollary 2.2, we have:

COROLlary 2.3. Let $(X, \leq)$ be a partially ordered set and $G$ be a G-metric on $X$. Let $F: X \times X \rightarrow X$ and $g: X \rightarrow X$ such that $F$ has the mixed $g$-monotone property. Suppose there exist non-negative real numbers $\alpha, \beta$ with $\alpha+\beta<1$ such that

$G(F(x, y), F(u, v), F(w, z)) \leq \alpha G(g x, g u, g w)+\beta G(g y, g v, g z)$,

for all $x, y, u, v, w, z \in X$ with $g w \preceq g u \preceq g x$ and $g y \preceq g v \preceq$ $g z$. Suppose that $F(X \times X) \subseteq g(X)$ and $g(X)$ is a complete subset of $X$. Assume also $X$ satifies:

(i) if a non-decreasing sequence $\left(x_{n}\right)$ is such that $x_{n} \rightarrow x$, then $x_{n} \preceq x$ for all $n$,

(ii) if a non-increasing sequence $\left(y_{n}\right)$ is such that $y_{n} \rightarrow y$, then $y \preceq y_{n}$ for all $n$. If there exist $x_{0}, y_{0} \in X$ such that $g x_{0} \preceq$ $F\left(x_{0}, y_{0}\right)$ and $F\left(y_{0}, x_{0}\right) \preceq g y_{0}$, then $F$ and $g$ have a coupled coincidence point, that is, there exists $(x, y) \in X \times X$ such that $g x=F(x, y)$ and $g y=F(y, x)$.

REMARK 2.4. In Corollary 2.3 taking $g$ to be identity function and alpha $=\beta=\frac{k}{2}(k \in[0,1))$, we get Theorem 3.1 of Choudhary and Maity [9] which is also stated here in this paper as Theorem 1.16. Further, above corollary is also an extension of Corollary 3.1 and Corollary 3.2 which are special case of main result of Aydi et al. [5].

REMARK 2.5. If in the theorem 3.1 and in both of corollary the mappings are compatible then the results will remain true.

Next our aim is to prove the uniqueness of coupled fixed point in the above theorem. For this, note that if $(X, \leq)$ is partially ordered set, then we endow the product space $X \times X$ with following partial order:

for $\quad(x, y),(u, v) \in X \times X, \quad(u, v) \leq(x, y) \Longleftrightarrow u \leq x, y \leq v$.

THEOREM 2.6. In addition to the hypotheses of Theorem 1.17 suppose that for every $(x, y),\left(x^{*}, y^{*}\right) \in X \times X$, there exists a $(u, v) \in X \times X$ such that $(F(u, v), F(v, u))$ is comparable to $(F(x, y), F(y, x))$ and $\left(F\left(x^{*}, y^{*}\right), F\left(y^{*}, x^{*}\right)\right)$ and, also $F$ and $g$ are weakly compatible. Then $F$ and $g$ have a unique coupled common fixed point. Moreover, the common fixed of $F$ and $g$ is of the form $(u, v)$ for some $u \in X$

PROOF. From theorem 1.17 the set of coupled coincidence point is non-empty. Suppose $(x, y)$ and $\left(x^{*}, y^{*}\right)$ are coupled coincidence point of $F$ and $g$, that is, $g x=F(x, y), g y=F(y, x)$ and $g x^{*}=F\left(x^{*}, y^{*}\right), g y^{*}=F\left(y^{*}, x^{*}\right)$. Now we show

$$
g x=g x^{*} \quad \text { and } \quad g y=g y^{*} .
$$

By the assumption, there exists $(u, v) \in X \times X$ such that $(F(u, v), F(v, u))$ is comparable to $(F(x, y), F(y, x))$ and $\left(F\left(x^{*}, y^{*}\right), F\left(y^{*}, x^{*}\right)\right)$. Put $u_{0}=u, v_{0}=v$ and choose $u_{1}, v_{1} \in$ $X$, so that $g u_{1}=F\left(u_{0}, v_{0}\right)$ and $g v_{1}=F\left(v_{0}, u_{0}\right)$. Then, repeating the same argument, we can inductively define sequences $\left\{g u_{n}\right\}$ and $\left\{g v_{n}\right\}$ where

$$
g u_{n}=F\left(u_{n-1}, v_{n-1}\right) \text { and } g v_{n}=F\left(v_{n-1}, u_{n-1}\right) \quad \forall n \in \mathbb{N} \text {. }
$$

Hence $(F(x, y), F(y, x))=(g x, g y)$ and $(F(u, v), F(v, u))=$ $\left(g u_{1}, g v_{1}\right)$ are comparable. Without loss of generality, suppose that $\left(g u_{0}, g v_{0}\right) \leq(g x, g y)$. Proceeding similarly as in [16], we check that $\left(g u_{n}, g v_{n}\right) \leq(g x, g y)$, for each $n \in \mathbb{N}$.
Since $g u_{n} \preceq g x$ and $g y \preceq g v_{n}$, using the contractive condition 2.11, we have

$$
\begin{aligned}
& G\left(g x, g x, g u_{n}\right)=G\left(F(x, y), F(x, y), F\left(u_{n-1}, v_{n-1}\right)\right) \\
& \leq p G\left(F\left(v_{n-1}, u_{n-1}\right), g y, g y\right) \frac{G\left(F(x, y), g x, g u_{n-1}\right)}{1+G\left(F(y, x), g y, g v_{n-1}\right)} \\
& +\alpha G\left(g x, g x, g u_{n-1}\right)+\beta G\left(g y, g y, g v_{n-1}\right) \\
& +L \min \left\{\left(G\left(F(x, y), g x, g u_{n-1}\right), G\left(F\left(u_{n-1}, y_{n-1}\right), g x, g x\right),\right.\right. \\
& \left.G\left(F(y, x), g y, g v_{n-1}\right), G\left(F(x, y), g x, g u_{n-1}\right)\right\}
\end{aligned}
$$

that is,

$$
G\left(g x, g x, g u_{n}\right) \leq \alpha G\left(g x, g x, g u_{n-1}\right)+\beta G\left(g y, g y, g v_{n-1}\right) .
$$

Repeating the same reasoning, we obtain

$$
G\left(g y, g y, g v_{n}\right) \leq \alpha G\left(g y, g y, g v_{n-1}\right)+\beta G\left(g x, g x, g u_{n-1}\right) .
$$

Adding 2.14 to 2.15, we have

$G\left(g x, g x, g u_{n}\right)+G\left(g y, g y, g v_{n}\right)$

$$
\begin{aligned}
& \leq(\alpha+\beta)\left[G\left(g x, g x, g u_{n-1}\right)+G\left(g y, g y, g v_{n-1}\right)\right] \\
& \leq \cdots \\
& \leq(\alpha+\beta)^{n}\left[G\left(g x, g x, g u_{0}\right)+G\left(g y, g y, g v_{0}\right)\right] .
\end{aligned}
$$

Since $\alpha+\beta<1$, taking the limit as $n \rightarrow \infty$, we get

$$
\lim _{n \rightarrow \infty}\left[G\left(g x, g x, g u_{n}\right)+G\left(g y, g y, g v_{n}\right)\right]=0 .
$$

It implies that

$$
\lim _{n \rightarrow \infty} G\left(g x, g x, g u_{n}\right)=\lim _{n \rightarrow \infty} G\left(g y, g y, g v_{n}\right)=0 .
$$

Repeating the similar argument, we find that

$$
\lim _{n \rightarrow \infty} G\left(g x^{*}, g x^{*}, g u_{n}\right)=\lim _{n \rightarrow \infty} G\left(g y^{*}, g y^{*}, g v_{n}\right)=0 .
$$

By (2.16), 2.17) and the uniqueness of the limit, we get that $g x=$ $g x^{*}$ and $g y=g y^{*}$. Thus, we proved 2.13.

Repeating the same argument, we prove that $g x=g y^{*}$ and $g y=$ $g x^{*}$. Thus $g x=g y$. Therefore, $(g x, g y)$ is unique coupled point of coincidence of $F$ and $g$. Now, let $g(x)=u$. Then we have $u=g x=F(x, x)$. By w-compatibility of $F$ and $g$, we have

$$
g u=g(g x)=g(F(x, x))=f(g x, g x)=F(u, u) .
$$

Then $(g u, g u)$ is coupled point of coincidence of $F$ and $g$. Consequently $g u=g x$. Therefore, $u=g u=F(u, u)$. Hence $(u, u)$ is unique common coupled fixed point of $F$ and $g$.

EXAMPLE 1. Let $X=[0,2]$ and $G(x, y, z)=(|x-y|+\mid y-$ $z|+| z-x \mid)$ for all $x, y$, in $X$ be G-metric defined on $X$. Then, $(X, \preceq)$ is a partial ordered set with natural ordering of real numbers. Let $g: X \rightarrow X$ and $F: X \times X \rightarrow X$ be defined as $g(x)=x / 2$ for all $x$ in $X$ and

$$
F(x, y)=\left\{\begin{array}{l}
(x-y / 2)^{2}, \quad \text { if } \quad x, y \in[0,1], x \leq y \\
0, \quad \text { if } x<y .
\end{array}\right.
$$

Clearly, $F(X \times X) \subseteq g(X)$, also F obeys mixed g-monotone property. Let $x_{n}$ and $y_{n}$ be two sequences in $X$ defined respectively by

$$
x_{n}=2+1 / n \text { and } y_{n}=1-1 / n,
$$


then we have by letting $n \rightarrow \infty$

$$
\begin{array}{r}
g\left(F\left(x_{n}, y_{n}\right)\right)=g(F(2+1 / n, 1-1 / n))=g\left(\frac{1+2 / n}{2}\right)^{2} \\
=g(1 / 4)=1 / 8 \neq 1 / 16=F\left(g x_{n}, g y_{n}\right) .
\end{array}
$$

Also

$$
g(F(1,0))=g(1 / 4)=1 / 8 \neq 1 / 16=F(g 1, g 0) .
$$

Which shows that the mappings $F$ and $g$ are neither compatible nor commutative, but obviously the are w-compatible. So, this example is not applicable to known results. Also the mappings satisfies all the condition of theorem 3.1. Hence $(0,0)$ in coupled fixed point of $F$ and $g$.

\section{REFERENCES}

[1] M. Abbas and B.E. Rhoades, Common fixed point results for non-commuting mappings without continuity in generalized metric spaces, Appl. Math. Computation. 215 (2009) 262-269.

[2] M. Abbas, M.A. Khan and S. Radenović, Common coupled fixed point theorem in cone metric space for $w$-compatible mappings, Appl. Math. Computation. (217) (2010) 195-202.

[3] M. Abbas, A.R. Khan and T. Nazir, Coupled common fixed point results in two generalized metric spaces, Appl. Math. Comput. (2011), doi:10.1016/j.amc.2011.01.006.

[4] H. Aydi, B. Samet and C. Vetro, Coupled fixed point results in cone metric spaces for $\tilde{w}$-compatible mappings, Accepted in Fixed Point Theory Appl., 2011, 2011:27 doi:10.1186/1687-1812-2011-27.

[5] H. Aydi, B. Damjanović, B. Samet, W. Shatanawi, Coupled fixed point theorems for nonlinear contractions in partially ordered $G$-metric spaces, Mathematical and Computer Modelling, Volume 54, Issues 9-10, November 2011, Pages 2443-2450.

[6] T.G. Bhaskar and V. Lakshmikantham, Fixed point theorems in partially ordered metric spaces and applications, Nonlinear Analysis. 65 (2006) 13791393.

[7] R. Chugh, T. Kadian, A. Rani, B.E. Rhoades, Property $P$ in $G$-metric spaces, Fixed Point Theory Appl, Vol 2010, Article ID 401684, 12 pages, 2010.

[8] B.S. Choudhury and A. Kundu, A coupled coincidence point result in partially ordered metric spaces for compatible mappings, Nonlinear Analysis. 73 (2010) 2524-2531.

[9] B.S. Choudhury and P. Maity, Coupled fixed point results in generalized metric spaces, Math. Comput. Modelling. (2011) doi:10.1016/j.mcm.2011.01.036.

[10] Lj. Ćirić, N. Cakić, M. Rajović and J.S. Ume, Monotone generalized nonlinear contractions in partially ordered metric spaces, Fixed Point Theory Appl, Vol 2008, Article ID 131294, 11 pages, 2008.

[11] Lj. Ćirić, D. Mihet and R. Saadati, Monotone generalized contractions in partially ordered probabilistic metric spaces, Topology Appl. 156 (17) (2009) 2838-2844.

[12] B.C. Dhage, Generalized metric space and mapping with fixed point, Bull. Cal. Math. Soc. 84 (1992) 329-336.

[13] B.C. Dhage, Generalized metric spaces and topological structure I, An. Stiint. Univ. Al.I. Cuza Iasi. Mat(N.S) 46 (2000) 3-24.

[14] B.C. Dhage, On generalized metric spaces and topological structure II, Pure Appl. Math. Sci. 40 (1-2) (1994) 37-41.

[15] B.C. Dhage, On continuity of mappings in $D$-metric spaces, Bull. Calcutta Math. Soc. 86 (6)(1994) 503-508.

[16] V. Lakshmikantham and Lj. Ćirić, Coupled fixed point theorems for nonlinear contractions in partially ordered metric spaces, Nonlinear Analysis. 70 (2009) 4341-4349.

[17] Z. Mustafa, A new structure for generalized metric spaces with applications to fixed point theory, Ph.D. thesis, The University of Newcastle, Callaghan, Australia, 2005.

[18] Z. Mustafa, H. Obiedat and F. Awawdeh, Some fixed point theorem for mapping on complete Gmetric spaces, Fixed Point Theory Appl, Vol 2008, Article ID 189870, 12 pages, 2008.
[19] Z. Mustafa and B. Sims, A new approach to generalized metric spaces, J. Nonlinear Convex Anal. 7 (2) (2006) 289-297.

[20] Z. Mustafa and B. Sims, Some remarks concerning $D$-metric spaces, in Proceedings of the International Conference on Fixed Point Theory and Applications, pp. 189-198, Yokohama, Japan, 2004

[21] Z. Mustafa and B. Sims, Fixed point theorems for contractive mappings in complete $G$-metric spaces, Fixed Point Theory Appl, Vol 2009, Article ID 917175 , 10 pages, 2009.

[22] Z. Mustafa, W. Shatanawi and M. Bataineh, Existence of fixed point results in $G$-metric spaces, Int. J. Math. Math. Sci, Vol 2009, Article ID 283028, 10 pages, 2009.

[23] A.C.M. Ran and M.C.B. Reurings, A fixed point theorem in partially ordered sets and some applications to matrix equations, Pror. Amer. Math. Soc. 132 (2004) 1435-1443.

[24] R. Saadati, S.M. Vaezpour, P. Vetro, and B.E. Rhoades, Fixed point theorems in generalized partially ordered $G-$ metric spaces, Math. Comput. Modelling. 52(2010) 797-801.

[25] W. Shatanawi, Fixed point theory for contractive mappings satisfying $\Phi$-maps in $G$-metric spaces, Fixed Point Theory Appl, Volume 2010, Article ID 181650, 9 pages, 2010

[26] W. Shatanawi, Partially ordered cone metric spaces and coupled fixed point results, Comput. Math. Appl. 60 (2010) 2508-2515. 